\title{
Aspectos de armonización asimétrica para la entrada y residencia de familiares de nacionales de terceros estados en la Unión Europea*, **
}

\author{
Aspects of asymmetric harmonization for entry and residence \\ of third-country national family members in the European Union
}

\author{
Encarnación La Spina \\ Investigador postdoctoral F. Braudel \\ LabexMed, CERIC Aix-Marseille Université
}

\begin{abstract}
Sumario: I. La Directiva 2003/86/CE como posible proyecto de armonización.-II. Algunos aspectos de armonización asimétrica para la entrada y residencia de familiares de nacionales de terceros Estados: Libro verde COM (2011) 735 final. II.1. La inclusión opcional de otros miembros en la familia nuclear. II.2. La posible exigibilidad de medidas de integración. II.3. La admisibilidad de controles e inspecciones para perseguir el fraude legis.-III. Conclusiones.
\end{abstract}

Resumen: Tras un decenio de la aprobación de la Directiva 2003/86/CE, tanto el Programa de Estocolmo como el Pacto Europeo sobre Inmigración y Asilo indican que la reagrupación familiar es una de las principales cuestiones objeto de desarrollo de la política comunitaria de inmigración. Sin embargo, la aplicación práctica de la Directiva da cuenta de la existencia de problemas y deficiencias en el margen de maniobra de los Estados miembros a la hora de implementar algunas de sus cláusulas opcionales. A tal propósito, este trabajo trata de plantear una revisión de las implicaciones jurídico-políticas que debe afrontar la inmigración familiar en el control del fraude legis, la inclusión de los miembros de la familia y la exigencia de posibles medidas de integración. Todos ellos aspectos que ponen de relieve no sólo las posibles deficiencias de la técnica legislativa del proceso de armonización europea sino también advierten de su incompatibilidad con el estándar internacional de derechos humanos.

* Recibido el 26 de mayo, aceptado el 18 de junio de 2015.

** Investigador postdoctoral del programa Fernand Braudel-IFER (International Fellowships for Experienced Researchers) y la Comisión Europea (Programme Action Marie Curie_COFUND-7éme PCRD) invitado en el LabexMed, CERIC-UMR 7318 reference 10-LABX-0090. Este trabajo se inscribe en el marco del Proyecto I+D+i del Ministerio de Economía y Competitividad, Derechos Humanos, sociedades multiculturales y conflictos, DER 2012-31771. 
Palabras claves: Directiva 2003/86/CE, familia, inmigración, medidas de integración, control del fraude.

Abstract: After a decade of the adoption of EU Directive 2003/86, the Stockholm Programme and the European Pact on Immigration and Asylum indicate that family reunification is one of the main issues for the European policy migration's development. However, the implementation of Directive shows the existence of problems and deficiencies in national level to assess the leeway to Member States when they are applying some of its optional clauses. Thereby, this paper is focused on reviewing legal-political implications of family immigration related to fraud control, family members inclusion and the exigency of possible integration measures. All these aspects highlight not only the technical shortcomings of the European harmonization process but also they warn their incompatibility with international human rights standard.

Keywords: EU Directive 2003/86, family, immigration, integration measures, fraud control.

\section{La Directiva 2003/86/CE como posible proyecto de armonización}

A partir de la década de los noventa, tanto el previsible impacto de los flujos migratorios por motivos familiares hacia la UE (Unión Europea) como el alto grado de disparidad entre los EEMM (Estados miembros) ha promovido la necesidad de regular desde el ámbito regional europeo la admisión de familiares de inmigrantes como manifestación directa del derecho a la vida en familia ${ }^{1}$. Para ello, la armonización de las legislaciones nacionales en materia de migración familiar se había concebido como un proceso a desarrollar en varias etapas, de las cuales la Directiva 2003/86/CE vendría a constituir tan sólo la primera de ellas. Desde su aprobación y conforme a lo establecido en su cláusula de emplazamiento, son precisamente las disposiciones que ofrecían la máxima flexibilidad, aquellas que podrían ser en un futuro objeto de revisión prioritaria - familiares reagrupables, concepto de reagrupante, condiciones de entrada, período de espera previo, acceso a un estatuto autónomo - para así permitir progresos paulatinos en el proyecto de armonización propuesto. Ello, era así porque las disposiciones más flexibles eran simultáneamente también las que permitían mayores divergencias internas en la conformación normativa de la reagrupación familiar.

1 Vid. ASÍN CABRERA, M.A.,"Reagrupación familiar y modelos de familia en la Unión Europea", en VVAA., Fronteras exteriores de la U.E. e inmigración a España: relaciones internacionales y derecho, Cuadernos de la Escuela Diplomática, 33, Tirant Lo Blanch, Valencia, 2007, pp. 153-174, p. 171. 
Por este motivo, el proyecto de armonización de la Directiva 2003/86/ $\mathrm{CE}$ ha ocupado un lugar relevante dentro de la arquitectura normativa e institucional europea. En particular, por ser la primera y más importante positivización adoptada en el ámbito de la UE después de la entrada en vigor del artículo 63.3 del Tratado de Ámsterdam, con excepción del Reino Unido, Irlanda y Dinamarca ${ }^{2}$. Una configuración de un marco normativo comunitario que también sería extrapolable a otras situaciones internas como al status de residente de larga duración, junto a un estatuto preferencial del reagrupante-refugiado ${ }^{3}$. Aunque, también sin duda, su relevancia se debe a perseguir por medio de una pionera disposición de Derecho Derivado un objetivo mediato e inmediato: la aproximación del estatuto jurídico de los nacionales de países terceros en las diferentes legislaciones nacionales respecto a cuestiones de empleo y familia ${ }^{4}$. Un ámbito, el familiar, que tenía un alto grado de disparidad ${ }^{5}$ en extremos tales como las condiciones en que debía ejercerse la reagrupación familiar, la exigencia de plazos previos de residencia legal o qué otros familiares distintos al esposo/a e hijos dependientes podrían ser autorizados a entrar o la definición concreta de hijos a efectos de reunificación.

Esta primera apuesta comunitaria por la aproximación queda latente ya desde la primera fase de la entonces nueva política migratoria común con la adopción de la Resolución de 1 de junio de 1993, a raíz de las Conclusiones de la Presidencia del Consejo Europeo de Copenhague ${ }^{6}$. La Re-

2 Vid. HAILBRONNER, K., "European immigration and asylum law under the Amsterdam Treaty", en Common market Law review, $n .^{\circ} 35$, 1998, pp. 1047-1067, en concreto pP. 1057-1058. Vid. SCHIBEL, Y., "Transposing EU Law on Legal Migration", en European Journal of Migration and Law, n. ${ }^{\circ}$ 6, 2005, pp. 395-404.

${ }^{3}$ Por tanto, quedan excluidos de la misma los miembros de familias de ciudadanos de la Unión que tienen su propio tratamiento jurídico. Vid. STAVER, A., "Free movement and the fragmentation of Family reunification rights", en European Journal of Migration and Law, n. ${ }^{\circ} 13,2013$, pp. 69-89.

${ }^{4}$ Sólo existe un antecedente a nivel comunitario, la Resolución de 11 de junio de 1993 sobre la armonización de las políticas nacionales en materia de reagrupación familiar (Documento SN 282/1/93 WGI 1497 REV). PEERS, S., ROGERS, N., EU immigration and asylum Law. Text and commentary, Koninklijke Brill N.V., Netherlands, 2006, p. 573-613, esp. p. 577.

${ }^{5}$ La enorme divergencia entre los EEMM ha sido constatada por la Comisión Europea por medio de la Inspección del documento de trabajo que sirvió de base a la resolución, y cuyos resultados aparecen en el Informe - no publicado - de dicho órgano, fechado el 13 de mayo de 1992, bajo el título Inspection of the Working Document of the European Comisión of 12 May $1992(\mathrm{~V} / 384 / 92)$.

${ }^{6}$ Documento SN 282/1/93 WGI 1497 Rev.1. Vid. BOELES, P.; KUIJER, A.: "Harmonization of Family Reunification", in MEIJERS, H., A new immigration law for Europe? The 1992 London and 1993 Copenhagen Rules on Immigration, Nederlands Centrum Buitenlanders, pp. 25-34, esp. p. 33. 
solución relativa a la armonización de las políticas nacionales en materia de reagrupación familiar si bien no era jurídicamente vinculante, enunció los primeros principios informadores para orientar las políticas nacionales de cada Estado miembro consideradas todas ellas como medidas transitorias que prepararían la posterior política migratoria común ${ }^{7}$. Las mismas, más tarde, se incluirían por medio de otra Resolución del PE (Parlamento Europeo) sobre la política europea de inmigración de 15 de julio de $1993^{8}$, en una propuesta de directiva marco sobre la inmigración y en particular una serie de directivas específicas que habían sido hasta entonces expresamente excluidas ${ }^{9}$.

Asimismo, este afán armonizador sería mayormente definido en otra propuesta de implementación contenida en la Resolución de 1 de junio de 1993, presentada por la Comisión en relación a un Convenio de admisión ${ }^{10}$, reformulando así en una version law ${ }^{11}$, un proyecto de armonización que fijaría las primeras medidas para la reagrupación familiar de nacionales de terceros países que residan legalmente en el territorio de los EEMM. Una versión que hasta llegar a ser definitiva se vería superada a su vez por sucesivas modificaciones a la propuesta inicial de diciembre de $1999^{12}$, incluyendo, entre otros, los extremos de los dictámenes del $\mathrm{PE}^{13}$ y del Consejo Económico y Social Europeo ${ }^{14}$, así como por una propuesta en octubre de $2000^{15}$,

7 Vid. para un estudio detallado del procedimiento de adopción de la Directiva, PEERS, S., ROGERS, N., op. cit nota 4, en concreto p. 577.

${ }^{8}$ DOCE C 225 de 20 de septiembre de 1993, p. 184 y ss. En especial el punto 1 f) y 12 de dicha resolución.

9 Aquellas relativas a la admisión de nacionales de terceros países como trabajadores por cuenta ajena, profesionales por cuenta propia y estudiantes, vid. arriba. Por ejemplo, también la Propuesta modificada de Acción Común relativa a la protección temporal de las personas desplazadas (art. 7.1) o la Propuesta de Reglamento del Parlamento Europeo y del Consejo que modifica el Reglamento núm. 1612/68 del Consejo relativo a la libre circulación de trabajadores dentro de la Comunidad, presentada por la Comisión de 26 de junio de 1998 (DOCE C 26813 de 27 de agosto de 1998).

10 Vid dos iniciativas previas y relacionadas como la citada propuesta de un Convenio de admisión GU V 337 del 7 de noviembre de 1997 y una resolución sobre medidas para contrastar los matrimonios ficticios GU C 382 del 16 de diciembre de 1997.

${ }^{11}$ COM (2000) 624 final-1999/0258 (CNS) también se aplicaría a los ciudadanos de la Unión que no ejerzan su derecho a la libre circulación. Vid. PEERS, S.; ROGERS, N., op. cit., nota 4, p. 580.

${ }^{12}$ COM 1999638 de 1 de diciembre de 1999. DOCE C 116 E de 26 de abril de 2000, p. 66.

13 Informe del Parlamento Europeo de 17 de julio de 2000, A5/201/2000 D.O.C.E. núm. C135/2000 p. 178.

14 Dictamen del Comité Económico y Social CES 588/2000, ponente Sra. Cassina, DOCE núm. C204/2000, p. 140.

15 COM (2000) 624 de 10 de octubre de 2000. DOCE C 62 E de 27 de febrero de 2001, p. 99 . 
donde se recogían la mayoría de las enmiendas del $\mathrm{PE}^{16}$, hasta la propuesta de mayo de $2002^{17}$ corolario de dos arduos años de debates y negociaciones ${ }^{18}$. Para llegar finalmente, sobre la base de esta segunda propuesta de la Directiva 2003/86/CE, a adoptar un acuerdo político ${ }^{19}$ que permitiría su aprobación sin debate en la Sesión n. ${ }^{\circ} 2525$ del 22 de septiembre de $2003^{20}$, si bien las enmiendas presentadas por el Parlamento ${ }^{21}$ fueron ampliamente rechazadas por la Comisión en su adopción formal.

Por tanto, desde su compleja aprobación que puso a prueba el mismo proceso de codecisión comunitario, han sido de igual modo numerosas las dificultades y, más si cabe, las críticas al proceso de armonización que planteaba esta norma de Derecho derivado ${ }^{22}$. Su objetivo explícito era establecer condiciones para el ejercicio del derecho y facilitar la integración de nacionales de terceros países dentro de una configuración mínima de los derechos y las necesidades sociales exigidas. De ahí que las principales críticas se han referido a la formulación dúctil y en ocasiones, altamente imprecisa, de la Directiva calificada como norma "de soft law derivado", teniendo en

16 Vid. BOELES, P., "Directive on Family Reunification: Are the Dilemmas resolved?" European Journal of Migration and Law, vol. 3, 2001, 1, pp. 61-71, en concreto p. 61. Vid. PEERS, S., ROGERS, N., EU immigration and asylum law, Text and commentary, op. cit., nota 4, p. 580-583. Council Docs. 5772/00, 10 febrero 2000, 6504/00 16 de marzo de 2000, 7507/00 28 de Julio de 2000 y 7997/00 28 de julio de 2000. Vid. Council doc. 9738/00 and 9739/00 de 28 de junio de 2000. Discussion continued under the Swedish Council presidency which completed the third reading of the proposal. Vid. Council docs. 5682/01 31 de enero de 2001; 6450/01 6 de marzo de 2001 y 7144/01, 23 de Marzo de 2001.

17 COM (2002) 225 de 2 de mayo de 2002. DOCE C 203 E de 27 de agosto de 2002, p.136. Esta tercera propuesta fue objeto de dictamen por parte del PE el 17 de julio de 2002 CES 857/2002, ponente Mengozzi y por el Comité de las regiones el 20 de noviembre de 2002, CDR 243/2002 ponente Sra. Coleman DOUE núm. C73/2003, p. 16.

18 Vid. PEERS, S., ROGERS, N., op. cit., nota 4, p.583-590. Vid. Council doc. $10857 / 029$ de agosto de 2002 (outcome of working party, 8 y 26 de julio de 2002). Council doc. $11787 / 0230$ de septiembre de 2002, outcome of proceedings of working party 5-6 y 18-19 de septiembre de 2002. Council doc. 13053/02 23 de octubre de 2002, outcome of proceedings of working party 1-2 de octubre de 2002, council doc. 13968/02 12 de noviembre de 2002 y Council doc. 14272/02 26 de noviembre de 2002, outcome of proceedings of working party 12 y 13 de noviembre de 2002 .

19 Acuerdo político del Consejo Sesión n. ${ }^{\circ} 2489,27$ y 28 de febrero de 2003 Boletín UE, 1-2 2003, punto 1. 4.16. QUIRÓS FONS, A., "Derecho Comunitario de extranjería. Directiva 2003/86/CE sobre reagrupación familiar y reforma del Derecho interno español," en Anales de Derecho, n. . 21, 2003, p. 383-415.p. 398.

${ }^{20} \mathrm{CNS} / 2001 / 0074$, n. $^{\circ} 6912 / 03$.

21 Dictamen Parlamento europeo de 9 de abril de 2003 A5/86/2003.

22 Vid. DE BRUYCKER, P., Le niveau d'harmonisation législative de la politique européenne d'immigration et d'asile" en JULIEN-LAFERRIERE, F., LABAYLE, H., La politique européenne d'immigration et d'asile : bilan critique cinq ans après le traité d'Amsterdam, Bruylant, Bruxelles, 2005, pp. 45-75, esp. p. 67. 
cuenta la amplitud del margen de apreciación estatal o la parquedad de las disposiciones vinculantes que rebajaban la intensidad de su "aparente" objetivo armonizador. No en vano, más que la superficialidad del derecho nacional ${ }^{23}$ se estimulaba la continuación de las entonces 24 políticas de reagrupación nacionales diversas, dotándolas de suficiente desenvoltura para terminar proyectando las prácticas y legislaciones nacionales más conservadoras o de mayor trayectoria migratoria.

De este modo, en el ámbito de la UE y a escala internacional, la Directiva 2003/86/CE y su aplicación práctica no dejaría de tener una amplia repercusión práctica en el ejercicio de derechos y libertades para los nacionales de terceros países ${ }^{24}$ que no siempre habían mantenido explícitamente tal reconocimiento ${ }^{25}$. Precisamente, la importancia de la protección del derecho a la vida en familia radica en varios de los principales instrumentos internacionales de protección de los derechos humanos:

1. El CEDH (Convenio Europeo para la Protección de los Derechos Humanos y de las Libertades Fundamentales) (1950,) cuyo artículo 8 es fundamental al reconocer a toda persona el derecho a que se respete su vida privada y familiar. Este precepto ha sido ampliamente completado por la jurisprudencia del TEDH (Tribunal Europeo de Derechos Humanos ${ }^{26}$ ). Han sido diversos los in-

${ }^{23}$ OOSTEROM-STAPLES, H., "The Family Reunification Directive: A Tool Preserving Member State Interest or Conducive to Family Unity?"; en BALDACINI, A., GUILD, E. and TONER, H. (eds.), Whose Freedom, Security and Justice? . EU Immigration and Asylum Law and Policy. Oxford and Pórtland, Oregon, Hart Publishing, 2007,p. 452,

${ }^{24}$ Sobre la formulación práctica de un derecho teóricamente asumido, vid. los trabajos de GÓMEZ CAMPELO, E., "El derecho a la reagrupación familiar según la Directiva 2003/86/ CE", en Actualidad Administrativa, Madrid, 2000, pp. 1551-1560, en concreto p. 1552. Y de la misma autora, GÓMEZ CAMPELO, E., "La compleja aplicación de la Directiva 2003/86/ CE sobre el derecho a la reagrupación familiar", en Revista española del Tercer sector, n. ${ }^{\circ} 12,2009$, pp. 73-99.

${ }^{25}$ En cambio, hay varias evidencias de que tal reconocimiento no es una cuestión pacífica en las legislaciones nacionales. Por ejemplo, la postura adoptada por Austria durante las negociaciones, dónde se opuso a la creación de un derecho europeo a la reunificación familiar, por considerar que este derecho excedería la garantía contenida en el artículo 8 del CEDH. Documento del Consejo 5772/00 de 10 de febrero de 2000. Así mismo, la postura de Bélgica declarando que el término derecho le planteaba problemas al no reconocer su legislación nacional tal derecho. Ante estas alegaciones, la Presidencia decidió someter al CEIFA la cuestión: ¿Debe considerarse la reagrupación familiar un derecho cuyo ejercicio está sometido al cumplimiento de determinadas condiciones? Documento del Consejo 7675/1/00 de 10 de abril del 2000.

26 Vid. Sentencia TEDH de 28 de noviembre de 1996 Ahmut/ Países Bajos (Recueil des arrêts et décisions 1996-VI apartados 63 y 67). Sentencia del TEDH de 28 de mayo de 1985, Abdulaziz, Cabales y Balkandali/ Reino Unido (Series A n. ${ }^{\circ}$ 94) Ahmut c. Pays bas du 28 novembre 1996, recueil des arrêts et décisions, 63. STEDH Sen/Países Bajos de 21 de diciem- 
tentos fallidos de derivar un derecho a la reagrupación familiar del artículo 8 del $\mathrm{CEDH}^{27}$, poniendo en evidencia como la lógica interpretativa del TEDH ha sido reconocer el derecho desde la excepcionalidad $^{28}$, por ser la modalidad más compatible con el amplio margen de apreciación de los Estados. En general, porque hay una línea de tendencia a la hora de interpretar restrictivamente los derechos protegibles atendiendo a meras circunstancias excepcionales del individuo y en cambio, más bien cierta benevolencia sobre el margen de apreciación de los Estados o la preeminencia de la soberanía estatal $^{29}$. Así se deriva en consecuencia que las únicas obligaciones derivadas para poder permitir la admisión de los extranjeros por medio de la reagrupación familiar son particulares y no genéricas ${ }^{30}$. $\mathrm{Su}$ reconocimiento está subordinado a un equilibrio entre la correlación hohfeldiana incompetencia-inmunidad del derecho del individuo a vivir en familia y el laissez faire del Estado a la hora de controlar la inmigración así como la residencia de los no nacionales.

2. Entre los tratados que constituyen la CIDH (Carta internacional de Derechos Humanos), la DUDH (1948), tras asegurar en su artículo 12 que nadie será objeto de injerencias, entre otras, en su vida privada y su familia, señala en su artículo 16.3 que "la familia es el elemento natural y fundamental de la sociedad y tiene derecho a la protección de la sociedad y del Estado". En la misma línea, el artículo 23.1 del PIDCP (Pacto de Derechos civiles y Políticos (1966), así como el 10.1 del PIDESC (Pacto de derechos económicos, sociales y culturales (1966), insisten en la importancia de conceder a la familia "la más amplia protección y asistencia posibles, especialmente para su constitución y mientras sea responsable del cuidado y la educación de los hijos a su cargo". No en vano, completando tales previsiones, el CDH (Comité de Derechos Humanos)

bre de 2001, n. ${ }^{\circ}$ 31465796. STEDH 1 de diciembre de 2005 asunto Tuquabo-Tekle c. Países Bajos, Sentencia del TEDH de 31 de julio 2008 asunto Darren Omoregie y otros/Noruega demanda n..$^{\circ}$ 265/07 apartado 57 y TEDH 31 de enero de 2006, caso Rodrigues da Silva et Hoojkamer c. Pays-Bas-requête n. ${ }^{\circ} 50435199$.

27 VARGAS GÓMEZ-URRUTIA, M., "La dimensión familiar de la inmigración y el derecho a la reagrupación familiar", en Anuario de la escuela de Práctica Jurídica. UNED, n. ${ }^{\circ} 1$, Madrid, 2006, pp. 1-14, en concreto pp. 4 y 5.

${ }^{28}$ SAROLÉA, S., Droits de l'homme et migrations. De la protection du migrant aux droits de la personne migrante, Bruyllant, Bruxelles, 2006, p. 367 y p. 609.

${ }_{29}$ MOCK, H., "Le droit au respect de la vie privée et familiale, du domicile et de la correspondance (article $8 \mathrm{CEDH}$ ) à l'aube du XXI siècle", en Revue universelle des Droits de l'homme, n. ${ }^{\circ} 10,1998$, pp. 237-246, en concreto p. 246.

${ }^{30}$ GRANT, P., La protection de la vie familiale et de la vie privée en droit des étrangers, Helbing \& Lichtenhahn, Bâle, Genève, Munich, 2000, p. 299. 
en repetidas ocasiones ha centrado su labor interpretativa y cuasijudicial en la protección de la vida familiar de los inmigrantes, reconociendo como señala Vedsted-Hansen "un amplio margen de apreciación cuando deciden si conceder una autorización de residencia a un extranjero para reunirse con los miembros de su familia residentes en este territorio" ${ }^{31}$. Así, desde un primer momento, indirectamente, el CDH en su Comentario General n. ${ }^{\circ} 15$ de $1986^{32}$ establece la protección del Convenio, en ciertas circunstancias referidas, incluso a la entrada o residencia, si concurren consideraciones de no discriminación, prohibición de trato inhumano y respecto a la unidad familiar. Por lo tanto, aunque los Estados parte, están legitimados para admitir o no la residencia y entrada de los extranjeros en su territorio, no es una habilitación ilimitada, sobre todo si concurren las mencionadas circunstancias especiales ${ }^{33}$.

3. Otros textos promovidos por Naciones Unidas, inciden en la relevancia de la reagrupación familiar. Paradigmática en este sentido sería la CDN (Convención sobre los Derechos del Niño (1989) que recoge en su artículo 10.1 en el caso de los menores que la solicitud del derecho a la reunificación familiar sea atendida de modo positivo, humanitario y expeditivo; por su parte el CIPDTM (Convenio Internacional sobre la protección de los derechos de los trabajadores migrantes y de sus familias (1990), se ocupa en su artículo 44 de reconocer el derecho a la reagrupación familiar, si bien no puede dejar de señalarse que, de momento, la relevancia de este último convenio es relativa en el ámbito de la UE puesto que ninguno de sus Estados, tampoco España, lo han ratificado aunque entró en vigor en julio de 2003.

4. La CSE (Carta Social Europea 1961 y su versión revisada de 1996), en el ámbito regional europeo, en su artículo 16 al ocu-

31 Vid. VEDSTED-HANSEN, J., "Migration and the right to family and private life", in CHETAIL, V., Mondialisation, migration et droits de l'homme: le droit international en question, Vol. II, Bruylant, Bruxelles, 2007, pp. 690-722. esp. p. 708; NOWAK, M., UN Covenant on Civil and Political Rights, CCPR Commentary, $2^{\text {nd }}$ revised edition, Kehl, NP, Engel, 2005, p. 393 y JOSEPH, S., The international Covenant on Civil and Political Rights, Cases, Materials and Commentary, Second Edition-Oxford University Press, 2004, pp. 489 y 591-604.

${ }^{32} \mathrm{Vid}$. General Comment $\mathrm{n}^{\circ} 15$ the position of aliens under the Covenant Twenty-seven session 1990, p. 140 en HRI/GEN/1/Rev.7 12 may 2004 International Human Rights Instruments Compilation of General Comments and General Recommendations adopted by Human rights Treaty bodies.

33 Vid. General Comment n. 19 article 23 (the family) Thirty-ninth session 1990, p. 149 en HRI/GEN/1/Rev.7 12 may 2004 International Human Rights Instruments Compilation of General Comments and General Recommendations adopted by Human rights Treaty bodies. 
parse de las condiciones de vida indispensables para un pleno desarrollo de la familia, entendiendo ésta como un pilar central de la sociedad. Más adelante el artículo 19.6 establece expresamente el compromiso de "facilitar la reagrupación de los trabajadores extranjeros a los que se les permite establecerse en el territorio del Estado parte". Desde una perspectiva semejante, el CETM Convenio relativo al estatuto jurídico del trabajador migrante reconoce en su artículo 12.1 el derecho a la reagrupación familiar y, especialmente, en el artículo 7 de la CDFUE (Carta de Derechos fundamentales de la Unión Europea).

Ahora bien, con independencia de las obligaciones internacionales en los EEMM para la protección del derecho a la vida familiar y, sobre todo, pese a las variantes terminológicas o las apreciaciones valorativas expuestas por parte de la doctrina sobre el contenido y el nomen iuris ${ }^{34}$ de la Directiva, el mínimo común denominador sobre el derecho a la reagrupación familiar ha quedado mayormente protegido en el ámbito comunitario y a la par, "removido de un exclusivo y excluyente control nacional"35. La previsión sustantiva del artículo 4.1 de la Directiva que resulta obligatoria para los EEMM en los términos expeditivos de "autorizarán la entrada y la residencia de ciertos familiares", so pena del llamado efecto directo comunitario, es aplicable incluso en el caso de ausencia o incorrecta transposición en el ordenamiento jurídico de los Estados Miembros ${ }^{36}$.

34 Vid. CHOLEWINSKI, R., "Family Reunification and Conditions Placed on Family Members: Dismantling a Fundamental Human Right?" en European Journal of Migration and Law, n. ${ }^{\circ} 4,2002$, pp. 271-290, en concreto p. 272. Vid. también SCHAFFRIN, D., "Which Standard for family reunification of third-country nationals in the European Union", in CARLIER, J.Y., Immigration and asylum law of the EU: current debates, Bruylant, Bruxelles, 2005, pp. 90-143, en concreto, p. 99. CORTES MARTIN, J.M., “ Immigration et regroupement familial dans l'Union européenne: un droit à géométrie variable? ", en Revue du droit de l'Union européenne, n. ${ }^{\circ} 4,2005$, pp. 721-759, especialmente, p. 748 y SIRIANNI, G., Il diritto degli stranieri alla unità familiare, Familia Quaderni diretti da Salvatore Patti, n. ${ }^{\circ}$ 6, Milano, 2006, esp. p. 37-38.

35 Vid. IGLESIAS SÁNCHEZ, S., "El valor de la directiva 2003/86/CE sobre reagrupación familiar a la luz de los derechos fundamentales y de la sentencia del TJCE", en Revista de Derecho Comunitario Europeo, n. ${ }^{\circ}$ 26, 2007, pp. 125-153, en concreto p. 148.

36 Vid. Comisión Memo/05/348, 3 oct. 2005. Los seis Estados Miembros fueron Bélgica, Estonia, Letonia, Lituania, Polonia y Eslovenia. Por ello, la Comisión por medio de Decisión de 28 de junio de 2006, ha presentado algunos dictámenes motivados con base al artículo 226 del TCE contra Bélgica, Chipre, Alemania, Estonia, Grecia, Finlandia, Francia, Italia, Luxemburgo y Malta. El 12 de diciembre de 2006, la Comisión decidió iniciar el procedimiento ante el TJCE contra Alemania, Italia, Luxemburgo y Malta, mientras que estimó archivar tal procedimiento respecto a Bélgica, Estonia, Grecia, Francia, Finlandia. El recurso contra Luxemburgo fue interpuesto el 7 de febrero de 2007. Asunto C-57/07. El recurso contra Malta fue interpuesto el 15 de febrero de 2007. Asunto C-87/07. DOUE de 14 de abril de 2007. El re- 
De igual modo, esta voluntad de armonizar el derecho a la reagrupación familiar como vía de integración preferente ha sido resuelta de forma más exitosa gracias a la labor fiscalizadora del propio TJUE (Tribunal de Justicia de la Unión Europea), que ha sabido avanzar, aunque lentamente, en el tratamiento de la reagrupación familiar como derecho para los nacionales de terceros Estados. Una fase ya prácticamente consolidada con respecto a las garantías de este derecho para los familiares de los ciudadanos comunitarios que ejercen su libertad de circulación ${ }^{37}$ a la luz de las últimas cuestiones prejudiciales planteadas por el Consejo de Estado holandés ${ }^{38}$. Por el contrario, una lectura distinta se infiere del tratamiento jurisprudencial aplicado en la tutela de la familia íntegramente constituida por nacionales de terceros Estados antes y después de la adaptación de la Directiva 2003/86/UE. Las decisiones del Tribunal han oscilado entre una primera fase circunscrita al ámbito estrictamente competencial ${ }^{39}$, hasta el desarrollo de nuevas formas indirectas de contención del margen de apreciación ${ }^{40}$, avaladas por la postura de la Abogada General en favor de la actuación del Consejo ${ }^{41}$, en el asunto $\mathrm{C} / 540 / 03$, que ha considerado infundadas las alegaciones del $\mathrm{PE}^{42}$ bajo el argumento dudoso de ser limitaciones preventivas y no "unas derogaciones talladas a la medida de los Estados miembros"43. Éstas últimas no sólo cuestionan el "alcance armo-

curso contra Italia fue interpuesto el 19 de febrero de 2007. Asunto C-91/07. DOUE de 14 de abril de 2007. Y por último, el recurso contra Alemania fue interpuesto el 3 de abril de 2007. Asunto C-192/07. DOUE de 26 de mayo de 2007.

37 Entre otras, en el asunto Mrax de 25 de julio 2002, García Avello de 2 de octubre de 2003, Chen de 19 de octubre de 2004, Zambrano de 8 de marzo 2011, y Maahanmuuttovirasto de 6 de diciembre de 2012, tiende a decantarse por esta opción pese a no ser totalmente favorables a una ampliación de la cobertura del llamado "paraguas comunitario".

38 TJUE del 12 de marzo de 2014, Asunto C-456/12: la situación de los Sres. O. y B, así como Asunto C-457/12: la situación de las Sras. S. y G.

39 Vid. sentencia TJUE de 17 de abril de 1997, Kadiman, (C-351/95), p. 54; y sentencia TJUE de 30 de septiembre de 1987, Demirel, (C-12/86), p. 28.

40 Vid. Recurso Parlamento europeo de 22 diciembre 2003, Asunto C-540/03, DOUE núm. C47/2004, p. 21. Vid. MARTIN, D., "Comments on N.v. Inspecteur van de Belastingdienst Oost/cantor Almelo (Case C-470/04 of 7 September 2006) European Parliament v. Council (Case C-540/03 of 27 June 2006) and Tas-Hagen and Tas (Case C-192/05 of 26 October 2006)", en European Journal of Migration and Law, n. .9, 2007, pp. 141-157.

41 Vid. De BRUYCKER, P., op. cit., nota 22, p. 61. BURGOURGUE-LARSEN, L., "L'Union européenne face a ses valeurs: entre utopie et réalisme dans la protection des migrants et des refugies" en MILLET-DEVALLE, A.S., L'Union européenne et a protection des migrants et des réfugiés, Colloque Nice 17-18 juin 2010, Pedone, Paris, pp. 281-288.

42 SCHAFFRIN, D.,"Which standard for family reunification of third-.country nationals in the European Union", in CARLIER, J.Y., Immigration and asylum law of the EU: current debates, Bruylant, Bruxelles, 2005, pp. 90-143.

43 Vid. DE BRUYCKER, P., op. cit., nota 22, esp. p. 52-63. 
nizador" de la Directiva ${ }^{44}$, sino que van más allá y plantean interrogantes sobre su conformidad con las exigencias derivadas de la protección de los derechos fundamentales.

\section{Algunos aspectos de armonización asimétrica para la entrada y residencia de familiares de nacionales de terceros Estados: Libro verde COM (2011) 735 final}

La mise en oeuvre del proceso de armonización plantea claroscuros sobre los avances y la "elasticidad" que admite la Directiva en base a la facultad reservada a los Estados de adoptar o conservar disposiciones más favorables ${ }^{45}$ dentro del amplio margen de discrecionalidad concedido ${ }^{46}$. Una muestra de ello son ciertos problemas transversales de transposición o aplicación incorrectas de la Directiva guiados, en parte, por las directrices promovidas en el Pacto Europeo sobre Inmigración y Asilo ${ }^{47}$ y su materialización en el Programa de Estocolmo (2010-2014) ${ }^{48}$.

${ }^{44}$ Según, SCHAFFRIN, D., op. cit., nota 42, p. 99.

45 Vid. COM (2008) 610/3 Report from the Commission to the European Parliament on the Council on the application of Directive 2003/86/CE. Estas propuestas de modificación se referirán prioritariamente a los arts. 3 (ámbito de aplicación), 4 (miembros de la familia), 7 (condiciones exigibles al reagrupante), 8 (tiempo mínimo de residencia para solicitar la reagrupación) y 13 (visado de entrada y permiso de residencia del miembro o miembros de la familia).

${ }^{46}$ GROENENDIJK, K. et al., The family reunification Directive in EU Member States. The first year of implementation, Centre for Migration Law, Nijmegen, 2007.

47 DE HART, B., "Love thy neighbour: family reunification and the rights of insiders", en European Journal of Migration and Law, n. ${ }^{\circ}$ 11, 2009, pp. 235-252. SPIJKERBOER, TH., "Structural Instability: "Strasbourg case law on Children's Family Reunion", en European Journal of Migration and law, n. ${ }^{\circ} 11,2009$, pp. 271-293. MCINTOSH, D., "Defining Family: a comment on the Family reunification provisions in the Immigration Act", en Journal Law and Social Policy, n. ${ }^{\circ}$ 3, 1988, pp. 104-115, esp. p. 104. APARICIO CHOFRE, L., "La aplicación de la directiva comunitaria sobre el derecho a la reagrupación familiar: cinco años después", en Cuadernos Constitucionales de la Cátedra Fadrique Furió Ceriol n. ${ }^{\circ}$ 57, 2008, pp. 143-162, esp. p. 157.

${ }^{48}$ Pacto europeo sobre Inmigración y asilo de la UE aprobado por el Consejo de la UE el 15 de octubre de 2008. N. ${ }^{\circ}$ doc. 13440/08 ASIM 72 Bruselas 24 de septiembre de 2008. Programa de Estocolmo - Una Europa abierta y segura que sirva y proteja al ciudadano (DOUE 2010/C 115/01) ap. 6.1. SOLANES CORELLA, A., "La apertura selectiva: nacionalidad y mercado frente a la movilidad humana" en DE LUCAS, J. y SOLANES CORELLA, A. (coord.), La igualdad en los derechos: claves de la integración, Dykinson, Madrid, 2009, pp. 67-96, esp.p. 90-94. AÑÓN ROIG, M.J., "Integración: una cuestión de derechos", en Arbor: Políticas migratorias y sociedad integrada, J. Velasco coord., vol. 186, n. ${ }^{\circ}$ 744, 2010, pp. 625-638, esp. p. 627. SOLANES CORELLA, A., “¿Cómo gestionar los flujos migratorios para potenciar la inmigración legal? Un análisis jurídico desde España”, en Migraciones in- 
En este orden de cosas es posible diferenciar cuestiones "interesadamente" objeto de menor armonización, entre otras, la concreción de un periodo de residencia superior a los dos años antes de la solicitud de la reagrupación y la disposición de una vivienda adecuada, así como recursos estables, suficientes ${ }^{49}$ o un seguro de enfermedad. Es decir, condiciones todas ellas que acrediten subvenir a las necesidades de los miembros de la familia reagrupada sin recurrir a la financiación pública. Respecto a estas últimas, el propio Tribunal ha tenido ocasión de fiscalizar el margen de apreciación dando respuesta a una solicitud aclaratoria requerida por el Raad van State (Consejo de Estado holandés) sobre el criterio "sin recurrir al sistema de asistencia social" objeto de transposición ${ }^{50}$. La referencia al sistema de asistencia social es un concepto con un significado independiente en el Derecho de la Unión Europea y no puede ser interpretado conforme a conceptos de derecho nacional. El TJUE se remonta así a su reiterada jurisprudencia según la cual, las exigencias derivadas de la protección de los principios generales reconocidos en el ordenamiento jurídico comunitario vinculan también a los EEMM cuando aplican la normativa comunitaria en virtud de tales obligaciones, sin menoscabar principios generales como la igualdad de trato o no discriminación.

Asimismo, mientras que la interpretación correctiva del TJUE ha empezado a examinar otras fórmulas facultativas que pueden imponer los Estados como son, entre otras, el sometimiento a un examen previo de integración al hijo mayor de 12 años que llegue independientemente del resto de la

ternacionales, vol. 4, n. ${ }^{\circ}$. 4, 2008, pp. 136-172, esp. p. 144-145. DE LUCAS MARTÍN, J.,"El marco jurídico internacional de las migraciones. Algunas consideraciones sobre la protección de los derechos humanos de los inmigrantes: acerca del derecho a ser inmigrante", MARIÑO MENÉNDEZ, F.M. (coord.), Un mundo sin desarraigo. El Derecho internacional de las Migraciones, Libros de la Catarata, Madrid, 2006, pp. 29-56, esp. p. 45. CARENS, J.H., "Who should get in? The Ethics of Immigration admissions", en Ethics and international affairs, n. ${ }^{\circ} 17,1,2003$, pp. 95-110.

${ }^{49}$ GROENENDIJK, K. et al., op. cit., nota 46, p. 26, España, junto a Chipre, Finlandia, Alemania y el Reino Unido no especifican en su legislación qué nivel de ingresos puede ser exigido. Por ejemplo, bareman la suficiencia de los recursos económicos con el salario mínimo, en el caso francés; unos recursos superiores o iguales al mínimo social, mientras que en Alemania y los Países Bajos, los recursos deben ser permanentes y estables. Por el contrario, el Reino Unido y Dinamarca exigían no recurrir a fondos públicos y que el residente subvenga a las necesidades de los miembros de su familia. Incluso países como Austria pedían que los miembros de la familia estuvieran cubiertos por la seguridad social, mientras que otros países como Luxemburgo, Finlandia y Suecia no exigían la existencia de recursos suficientes como condición para ejercer el derecho a la reagrupación familiar, antes de la adopción de sus legislaciones nacionales y, lo han incorporado tras la adopción de la Directiva.

50 Asunto C-578/08: Sentencia del TJUE (Sala Segunda) de 4 de marzo de 2010 (petición de decisión prejudicial planteada por Raad van State-Países Bajos)-Rhimou Chakroun/Minister van Buitenlandse Zaken. DOUE Serie C núm. 113, 1 de mayo de 2010. 
familia o su exclusión, la exigencia de una edad mínima previa a la solicitud de no más de 21 años y, la efectividad de la vida familiar ${ }^{51}$. En cambio, ni tan siquiera se ha abierto el debate sobre los límites a la exclusión del hijo de reagrupante poligámico ${ }^{52}$. Todo ello, sin perjuicio de otros extremos obviados por ser considerados menos sustanciales para el objetivo armonizador pese a la ausencia de simetrías como son, el procedimiento de solicitud del derecho, donde se establecen medidas de denegación de solicitud, retirada de permiso, denegación de renovación o expulsión en los supuestos de incumplimiento de las condiciones establecidas o por motivos de fraude, orden público, seguridad pública y salud pública.

La Directiva 2003/86/CE, ha logrado sistematizar en parte los requisitos para el ejercicio del derecho a la reagrupación familiar, la entrada y residencia de los miembros de la familia así como los extremos relacionados con el asilo. En cambio, no ha previsto un mayor desarrollo del apartado referente a los posibles aspectos prácticos derivados de fraudes, abusos y cuestiones procesales $^{53}$. La existencia de problemas de aplicación del derecho a la reagrupación familiar planteada por la Comisión europea en la elaboración del Libro verde advierte, como recuerda Cortés Martín, la previsible y controvertida naturaleza fragmentaria de este derecho en sede comunitaria ${ }^{54}$, junto al evidente grado de discrecionalidad depositada en manos de las administraciones nacionales como primera instancia para interpretar y hacer operativo el cumplimiento de tales condiciones. Este segundo aspecto, si bien podía y debía ser prioritario para la armonización de la Directiva, ha sido relegado a la lógica del laissez faire dando así mayor protagonismo a las cláusulas opcionales y a la consolidación de notables asimetrías en el contexto europeo.

Por ello, cabe la hipótesis que una gran parte de tales problemas de aplicación responden a posibles deficiencias derivadas de la técnica legislativa

${ }^{51}$ Según la intepretación del artículo 16.1 de la directiva a sensu contrario, "El Estado puede denegar una solicitud cuando un reagrupante y el miembro o miembros de su familia no hagan o hayan dejado de hacer vida conyugal o familiar efectiva".

52 Así, el artículo 4.4. párrafo segundo de la directiva puntualiza: "no obstante lo dispuesto en la letra c) del apartado 1, los Estados miembros podrán limitar la reagrupación familiar de los hijos menores de otro cónyuge y del reagrupante."

${ }^{53}$ Libro verde COM (2011) 735 final sobre el derecho a la reunificación familiar de los nacionales de terceros países que residen en la UE (Directiva 2003/86/CE), p. 21. ESPINO GARCÍA, S., "Respuestas a las cuestiones planteadas por el libro verde sobre el derecho a la reagrupación familiar: revisión de la directiva 2003/86/CE del Consejo, de 22 de septiembre de 2003, sobre el derecho a la reagrupación familiar de nacionales de terceros países residentes en la Unión Europea”, en Revista electrónica de estudios internacionales, n. ${ }^{\circ}$ 26, 2013, pp. 1-56.

54 Vid. CORTÉS MARTÍN, J.M., "Ciudadanos de la Unión vs. nacionales de terceros países: sobre la incipiente convergencia interpretativa del derecho europeo a la reagrupación familiar", en Revista general de Derecho europeo, n. ${ }^{\circ}$ 26, 2012, pp. 1-58, esp. p. 46-47. 
del proceso de armonización europea llevado a cabo por etapas ${ }^{55}$. Una técnica legislativa más proclive al uso reiterado de fórmulas abiertas según el orden y sistemática de los respectivos derechos internos, en detrimento de una mayor interpretación unitaria que vincule a todos los EEMM sobre la plausible contención del margen de apreciación ${ }^{56}$. Por ejemplo, bajo mi punto de vista, los "nuevos" y "futuros" problemas de aplicación práctica con incidencia más directa en el margen de apreciación de los Estados son y van a ser la inclusión opcional de otros miembros de la familia nuclear, la posible exigibilidad de medidas de integración así como los controles contra el fraude legis. Obviamente, hasta ahora lo son por su menor peso en el ápice corrector de la jurisprudencia regional europea, aunque si empiezan a interesarse las primeras instancias judiciales sobre los mismos dando cuenta de su complejidad ${ }^{57}$.

\section{II.1. La inclusión opcional de otros miembros en la familia nuclear}

El artículo 4 apartado 3, solamente obliga a garantizar la reunificación de la familia nuclear por lo que existe cierta libertad de decidir si se incluyen o no a otros miembros de la familia en cada legislación nacional. A pesar de que se trata sólo de una cláusula "opcional", más de la mitad de los EEMM han decidido incluir a los padres del reagrupante y/o de su cónyuge. Por el contrario, hay más reticencias a la hora de conceder el derecho a la reagrupación familiar para las parejas no casadas, aunque sí se enuncia en el artículo 4.3 la posibilidad de equiparar el cónyuge no casado de un país tercero que mantenga con el reagrupante una relación duradera debidamente probada o constituya con el mismo una pareja de hecho registrada.

55 ÁLVAREZ RODRÍGUEZ, A., "La transposición de directivas de la UE sobre inmigración. Las directivas de reagrupación familiar y de residentes de larga duración”, Fundación CIDOB , n. ${ }^{\circ} 8$, Barcelona, 2006, p. 1-122. Directiva 2003/86 CE del Consejo, de 22 de septiembre de 2003 (DOUE 2003 L 251/12). Según la clasificación de GROENENDIJK, K. "Three sets of Community Law Rules on Family Reunification: Directive 2004/38/EC, Decision 1/80 of the Association Council EEC-Turkey and Directive on the right to family reunification 2003/86/ EC". Vid. GROENENDIJK, K.,"Family Reunification as a Right under Community Law", en European Journal of Migration and Law, n. ${ }^{\circ}$ 8, 2006, pp. 215-230, esp. p. 216-217.

56 Por ejemplo, cláusulas de excepción son las que autorizan a los Estados miembros a escapar de aquellas disposiciones a las que no pueden consentir, fundamentalmente por impedirlo sus leyes nacionales. Las cláusulas de mantenimiento del statu quo son las que tienen por objetivo evitar que los Estados miembros utilicen las excepciones establecidas por la Directiva si no estuvieran previstas "por su legislación vigente en la fecha de aplicación de la presente Directiva". Y, por último, las cláusulas de emplazamiento, mediante las cuales se postergan las negociaciones difíciles durante dos años.

57 PASCOUAU, Y., Conditions for family reunification under strain. A comparative study in nine EU member states, European Policy Centre, Bruxelles, 2011, pp. 47-48. 
Este es el caso de Portugal, Bélgica, Dinamarca, España, Finlandia, los Países Bajos, Suecia y el Reino Unido. Mientras que para una amplia mayoría, las parejas de hecho no tienen derecho a la reunificación familiar, por ejemplo en Austria, Francia, Polonia y Chipre ${ }^{58}$. La Directiva incorpora como novedad la posible inclusión de este tipo de uniones no matrimoniales, pero dejando a los propios Estados la decisión opcional sobre su incorporación, y lo mismo ocurre en lo dispuesto en su artículo 4.5. Recientemente ha sido sometido a examen un caso ante el Tribunal respecto a la posibilidad brindada a los Estados de requerir una edad mínima de hasta 21 años para ser capaz de hacer efectiva la vida familiar por razones de integración o bien evitar matrimonios forzados ${ }^{59}$. En cualquier caso, tales previsiones no suplen posibles problemas administrativos como la determinación de elementos comunes en cada regulación interna respecto a la asimilación de la unión de facto y el vínculo matrimonial ${ }^{60}$, ni por otro lado, la determinación del cómputo de la edad límite atendiendo al momento de solicitud o la decisión de la reagrupación familiar ${ }^{61}$.

Por todo ello, es posible colegir que existe en el entorno europeo el acomodo de una definición claramente restrictiva de los beneficiarios de la reagrupación familiar y los derechos derivados de la misma ${ }^{62}$ por varias razones. Por una parte, se mantiene el principio de que los familiares de los que pretenden reagruparse se encuentren fuera del territorio del Estado miembro, salvo excepciones previstas por los Estados. Sin duda, la salvedad más notoria es la admisibilidad de familiares que se encuentran ya en el territorio, tal y como es recogida en la legislación portuguesa ${ }^{63}$. Y, por otra

58 GROENENDIJK, K. et al, op. cit., nota 46, vid. esp. p. 18-19.

59 Son cinco Estados miembros los que han establecido la edad mínima exigida en el máximo de 21 años previsto en la Directiva (Bélgica, Chipre, Lituania, Malta y los Países Bajos). Por otra parte, cabe destacar que hay varios Estados miembros que han establecido normas sobre la base de la mayoría de edad (Francia, Alemania y Suecia) y algunos otros que no han adoptado ninguna norma con respecto a la edad mínima exigida (Polonia, Portugal, Eslovenia y España).

${ }^{60}$ MARIN CONSARNAU, D., "Las uniones no matrimoniales como familiares reagrupables: problemática específica en Cataluña, en Revista de derecho migratorio y extranjería, n. ${ }^{\circ} 27,2011$, pp. 39-59, esp. pp. 43-45.

${ }^{61}$ MILIOS, G., "Family Reunification for Third-Country Nationals: Minimum Age for Spouses, Integration Measures and the Application of the Individual Assessment. Comments on Noorzia and Dogan" en European Journal of Migration and Law, n. ${ }^{\circ}$ 17, 2015, pp. 127-146.

${ }^{62}$ Los artículos 13, 14 y 15 de la Directiva establecen un mínimo necesario y condicionado: un permiso de residencia de un año renovable, el acceso a la educación, a un empleo y la formación profesional y el acceso a un permiso de residencia autónomo una vez cumplidos cinco años.

${ }^{63}$ LA SPINA, E., " El éxito de la integración de las familias inmigrantes en la normativa de extranjería portuguesa”, en Sociologia del Diritto, n.1, 2011, pp. 123-149. STRIK, T., DE HART, B. AND NISSEN, E., Family Reunification a barrier or facilitator of integration? A comparative study, European Commission, Brussels, 2013, pp. 110-112. 
parte, aunque se admite la posibilidad de reagrupar a los descendientes, se limita a los hijos menores de edad ya que los mayores de edad sólo podrán serlo por motivos de salud sin hacer extensible este núcleo familiar a otras realidades familiares actuales. A partir del 3 de octubre 2005, la acogida de disposiciones especiales relativas a la admisión de los niños mayores de 15 años muestran un perfil más restrictivo aunque puedan tener un alcance minoritario. Sólo es operativa en dos EEMM. Dinamarca, donde la edad límite general para los niños que buscan la reunificación familiar es de 15, mientras que en Alemania sólo se permite hasta la edad de 16 años. ${ }^{64}$

Sin embargo, la mayor exclusión opcional deriva de la reagrupación de ascendientes en línea recta y en primer grado articulada en el 4.2 a), que no admite ningún tipo de familiar colateral incluso hermanos en situación de dependencia. Es el caso por ejemplo de Francia, Bélgica y Polonia que no permiten la implementación de esta cláusula opcional para extender la línea ascendente en grado como si hace la mayoría de Estados por razones humanitarias o bien, la previsión del legislador español tras la reforma de la Ley orgánica 2/2009, que exige un autorización de residencia de larga duración para que el familiar reagrupante pueda solicitar la entrada por motivos familiares en favor de un ascendiente ${ }^{65}$.

Esta posible elasticidad del núcleo familiar ha dado lugar a interesantes diferencias entre los EEMM no tanto desde un punto de vista cuantitativo, sino también cualitativo a la hora de fijar la formación de las familias en destino ${ }^{66}$. Se limita así, libremente, la admisión de ciertos familiares a una determinada autorización de residencia o grado de dependencia ${ }^{67}$ que

${ }^{64}$ GROENENDIJK, K. et al., op. cit., nota 46, vid. esp. p. 17-18.

65 PASCOUAU, Y., op. cit., nota 57, p. 47-48.

${ }^{66}$ Por ejemplo según los datos estadísticos del Libro verde 15.11.2011 COM (2011) 735 final, sobre el derecho a la reunificación familiar de los nacionales de terceros países que residen en la UE (Directiva 2003/86/CE). p. 24. En 2010, el número total de permisos de residencia expedidos a nacionales de terceros países para reunirse con ciudadanos no pertenecientes a la UE por razones familiares, según la tipología del miembro de la familia, ha sido de 11,967 en Portugal, y 89,905 en España. En Portugal, el cónyuge/pareja que se reúne con un ciudadano no perteneciente a la UE asciende a 916, el menor que se reúne con un ciudadano no perteneciente a la UE es de 10,13 y, en cambio, la cifra es superior 10,038 en el caso de otro miembro de la familia que se reúne con un ciudadano no perteneciente a la UE. Mientras que en España, el cónyuge/pareja que se reúne con un ciudadano no perteneciente a la UE asciende a 19,140, el número de menores que se reúnen con un ciudadano no perteneciente a la UE es de 69,099. Y, en cambio para el caso de otro miembro de la familia que se reúne con un ciudadano no perteneciente a la UE no supera los 16,66.

67 Vid. LA SPINA, E., Familias transnacionales, sociedades multiculturales e integración: España, Italia y Portugal en perspectiva comparada, Dykinson, Madrid, 2011, p. 350 y ss, respecto a la situación de los ascendientes que son hermanos menores a reagrupar en Portugal o el requisito de autorización de residencia de larga duración para reagrupar a los ascendientes en España. 
enfatiza, si cabe más, las disimilitudes entre los Estados incluidos en el ámbito de aplicación de la Directiva 2003/86/CE. Una disimilitud que puede promover quizás analógicamente un llamado forum shopping a la hora de presentar en los diferentes EEMM la solicitud de entrada por reagrupación familiar. Habrá posiblemente una consideración ciertamente más o menos favorable para algunos familiares de nacionales de terceros países en función del Estado miembro que debe autorizar la misma.

\section{II.2. La posible exigibilidad de medidas de integración}

El artículo 7, apartado 2, permite a los EEMM exigir a los nacionales de terceros países que cumplan las medidas de integración, lo que no equivale a exigir ciertas condiciones de integración, como lo establecido en el artículo 5 apartado 2 de la Directiva 2003/109, sobre el estatuto de residentes de larga duración ${ }^{68}$. Éste fue uno de los requisitos más controvertidos y debatidos durante las negociaciones ${ }^{69}$, aunque también ampliamente reiterado en el diseño de la política de inmigración en el ámbito de la $\mathrm{UE}^{70}$.

68 ACOSTA ARCARAZO, D., "Misure e condizioni di integrazione per i cittadini di Paesi terzi nell'Unione europea. Un'analisi comparata e una valutazione della loro attuazione e dei limiti alla luce del diritto dell'Unione europea", en Diritto, immigrazione e cittadinanza, n. ${ }^{\circ}$ 2, 2012 p. 15-31, esp. p. 16-17.

69 Vid. algunas de las opiniones críticas de las ONG's de la propuestas de las Directivas: Immigration law publications' association (ILPA) and Migration Policy group (MPG) prepared for ILPA and MPG by PEERS, S., The ILPA/MPG Proponed Directives on Immigration and Asylum (Brussels/London MPG/ILPA 2000) p. 128-129. European Council on Refugee and exiles (ECRE) European Network against racism (ENAR) and MPG Guarding standardsshaping the agenda (ECRE, ENAR and MPG), Bruxelles, 1999, p. 20. PASCOUAU, Y., op . cit., nota 57, p. 7.

70 Vid. entre otros COM (2000) 757 final, de 22 de noviembre, Comunicación de la Comisión al Consejo y al PE sobre una política comunitaria de inmigración. Reiterada, por ejemplo, en COM (2001) 387 final, de 11 de julio, Comunicación de la Comisión al Consejo y al PE relativa a un método abierto de coordinación de la política comunitaria en materia de inmigración y COM (2003) 336 final, de 3 de junio, Comunicación de la Comisión al Consejo, al PE, al Comité Económico y Social Europeo y al Comité de la Regiones, sobre inmigración, integración y empleo. Comunicación de la Comisión, Programa de la Haya: diez prioridades para los próximos cinco años. Una asociación para la renovación europea en el ámbito de la libertad, la seguridad y la justicia, COM (2005) 184 final de 10.5.2005. Cfr. El programa de La Haya: consolidación de la libertad, la seguridad y la justicia en la UE (2005/C 53/01), Diario Oficial C 53 de 3.3.2006. Y, más recientemente, COM (2011) 455 final, de 20 de julio de 2011, Comunicación de la Comisión al PE, al Consejo, al Comité Económico y Social Europeo y al Comité de las Regiones "Agenda Europea para la Integración de los Nacionales de Terceros Países" COM (2012) 250 final, de 30 de mayo de 2012, Comunicación de la Comisión al PE y al Consejo, III Informe Anual sobre Inmigración y Asilo (2011). 
El propio TJUE tuvo oportunidad de incluir en la revisión del recurso del $\mathrm{PE}^{71}$, apreciaciones sobre los efectos de la instrumentalización del criterio de integración por parte de los Estados para la denegación del derecho a vivir en familia de un hijo mayor de 12 años.

Sobre este punto, concluyó que el margen de apreciación de los Estados en virtud del criterio de integración de los menores no difiere del reconocido por el TEDH, haciéndose eco de la opinión del propio Consejo que lo califica como una finalidad legítima que forma parte de la política de integración y a la par, proporcionada al objetivo perseguido. Tal amparo de los límites legítimos del artículo $8 \mathrm{CEDH}$, se utiliza como comodín para justificar el criterio de integración con respecto al artículo 4.1 y 4.6, así como el criterio de capacidad de acogida, en relación al artículo 8. Esto es, permite negar y cuestionar por razón de la edad la capacidad de integración del menor y se aleja de la vocación de facilitar la integración de los extranjeros en la sociedad de acogida ${ }^{72}$. E incluso la falta de definición de tal criterio u objetivo es contraproducente, ya que cada Estado, al fijar los límites de la autorización en la legislación aplicable, creará una gran incertidumbre jurídica sobre el grado de integración exigible a los hijos menores de edad entre 12 y 15 años. Aunque en idénticos términos, se defiende tajantemente el periodo de espera del artículo 8 de la Directiva, porque "persigue un fin legítimo de la política de inmigración, en concreto la integración eficaz de los miembros de la familia en la sociedad de acogida". No por ello, la doctrina de forma unánime ${ }^{73}$ ha cuestionado abiertamente la compatibilidad de tal contenido normativo, contraargumentando así la decisión del propio Tribunal.

Sin embargo, sobre la base de una política de integración distintos Estados de la Unión llevan algunos años, aplicando los denominados contratos o cursos de integración con el propósito de ajustar el modelo contractual de derechos y deberes del inmigrante. Así, con diferentes puntos de coincidencia pero también con importantes divergencias se han puesto en marcha

71 Vid. VELÁZQUEZ SÁNCHEZ, M.M., “¿La regulación del derecho a la reagrupación familiar o defensa de una política restrictiva de la inmigración? Comentario a la Sentencia del Tribunal de Justicia de las Comunidades Europeas de 27 de junio de 2006, C-504/2003”, en Revista General de Derecho Europeo, n. ${ }^{\circ} 12,2007$, pp. 1-35, en concreto p. 8-9. Vid. sentencia TJUE 27 de junio de 2006, asunto 540/03, apartado 22 y 23.

72 Vid. CORTÉS MARTÍN, J.M., "Tribunal de Justicia de la Unión Europea-Sentencia de 27.06.2006, Parlamento Europeo/Consejo, C-540/03-Restricciones al reagrupamiento familiar de nacionales de terceros países versus respeto de los derechos fundamentales", en Revista de Derecho Comunitario Europeo n. . 26, 2007, pp. 221 y 222. VELÁZQUEZ SÁNCHEZ, M.M., op. cit., nota 71, p. 14.

73 Vid. CHOLEWINSKI, R., op. cit., nota 34, esp. p. 274-276. 
como "hitos liberales"74 contratos o cursos de integración, exámenes de civismo y ciudadanía (vinculantes o no), en diferentes países.

En Suecia, Dinamarca, Finlandia, Países Bajos, Austria, Bélgica, Francia, Reino Unido, Estonia (dirigidos a la minoría rusa), Alemania y Suiza ${ }^{75}$. En su forma actual, la propia Directiva no da ninguna indicación precisa ${ }^{76}$ sobre esas medidas de integración o cómo deben aplicarse, pues sólo se usan en algunos EEMM ${ }^{77}$. Tres Estados miembros recurren, como condición previa a la admisión en su territorio, a tales medidas ${ }^{78}$, que exigen que los miembros de la familia realicen pruebas de conocimiento del idioma y de la sociedad de acogida o que firmen un contrato que les obliga a seguir

74 Vid. TRIADAFILOPOULOS, T., "Illiberal means to liberal ends? Understanding recent immigrant integration policies in Europe", en Journal of Ethnic and migration Studies, vol. 37, n. ${ }^{\circ} 6,2011$, pp. 861-880, esp. p. 879. DE LUCAS MARTÍN, J., "Sobre los fundamentos de la igualdad y del reconocimiento. Un análisis crítico de las condiciones de las políticas europeas de integración ante la inmigración". En VVAA, Inmigración e integración en la UE. Dos retos para el siglo XXI, Eurobask, Bilbao, 2012, pp. 11-92.

75 SOLANES CORELLA, A., "El buen inmigrante: regular e integrado". en REDUR n. ${ }^{\circ}$ 9, diciembre, 2011, pp. 99-125. STRIK, T., BÖCKER, A., LUITEN M. and VAN OERS, R., The INTEC project: synthesis report. Integration and naturalisation tests: the new way to European Citizenship, (última consulta, 15/05/2015)., http://www.ru.nl/publish/ pages/621216/synthesis_intec_finalmarch2011.pdf. CARRERA, S., "Nationality, immigration and "the Republican Integration" in France: Normativisation, expansionism and externalisation" en GUILD, E., GROENENDIJK, K., CARRERA, S., Illiberal liberal states: immigration, citizenship, and integration in the EU, Burlington, VT: Ashgate, Farnham, 2009, pp. 315-336. VAN OERS, R., ERSBØLL, E., KOSTAKOPOULOU, D., A Definition of belonging: Language and integration tests in Europe, Martinus Nijhoff, Leiden, 2010.

${ }^{76}$ Vid. MARTIN, D., "Comments on N.v. Inspecteur van de Belastingdienst Oost/cantor Almelo (Case C-470/04 of 7 September 2006) European Parliament v. Council (Case C-540/03 of 27 June 2006) and Tas-Hagen and Tas (Case C-192/05 of 26 October 2006)", en European Journal of Migration and Law, 9, 2007, p. 141-157. Vid. GROENENDIJK, K., "Legal concepts of integration in EU Migration Law", en European journal of Migration and Law, vol. 6, n. ${ }^{\circ}$. 2, 2004, p. 111-126, esp. p. 120.

77 Portugal y Eslovenia son los dos países que han adoptado medidas más sencillas para la integración sin prever un requisito específico para la misma. Vid. Migrant Integration Policy Index III, British Council, Bruselas, 2011, p. 14 y 16. España es valorada positivamente (octava posición) por ser uno de los países con políticas y marco normativo más flexibles o favorables a la integración, pero es una posición que le mantiene a distancia de otros como Suecia y Portugal, que son considerados referentes en tales políticas. PASCOUAU, Y., op. cit., nota 57, p. 5.

78 Dinamarca y Francia requieren conocimientos de idioma antes de la entrada y también acreditar la asistencia a cursos. En Holanda los miembros de la familia deben pasar un test de integración con contenido lingüístico y conocimiento de la sociedad holandesa, incluso se prevé en Holanda y Dinamarca que algunos grupos estén exentos. En cambio, es más habitual que los EEMM (Austria, Chipre, Francia y Eslovaquia) pidan la asistencia a cursos de integración o la superación de exámenes después de la admisión en el territorio. En cambio, Lituania y Reino Unido requieren los test de integración como condición necesaria para obtener la autorización de residencia permanente. 
cursos de educación cívica y, si es necesario, cursos de lengua, en el momento de su entrada ${ }^{79}$. Otros EEMM exigen a los miembros de la familia que respeten determinadas obligaciones sólo a la entrada, como que participen en cursos de integración (principalmente cursos de lengua). Mientras otros, como España e Italia, por el momento han recogido la voluntad de integrarse en términos abstractos de mayor o menor intensidad como un aspecto a valorar para la renovación de las autorizaciones de residencia ${ }^{80}$.

Por ejemplo, Austria es uno de los países que sí ha optado por articular por la vía jurídica un contrato de integración para todos aquellos nacionales de terceros países que, encontrándose dentro del ámbito de aplicación de la norma destinada básicamente a los inmigrantes, deseen obtener una autorización de residencia. El contrato tiene un doble contenido tanto cívico como lingüístico por el que el inmigrante se compromete a asistir a trescientas horas a cursos de lengua, alcanzando un nivel A2 de alemán, y a tener conocimiento de la vida austriaca en lo relativo a aspectos económicos, sociales y culturales. También en Alemania el programa de integración se prolonga durante tres años consecutivos, articulándose de distinta manera en función del nivel de estudios y capacitación de la persona concreta, puesto que un objetivo central es la incorporación al mercado de trabajo del inmigrante. La novedad consiste en dirigirlos a todas las categorías de nuevos inmigrantes, especialmente a los familiares reagrupados, que se han convertido en destinatarios ${ }^{81}$.

Ahora bien, uno de los exponentes de mayor evolución hacía políticas reduccionistas y claramente vinculantes por la vía jurídica es Holanda. A diferencia del resto, la referencia normativa a lo que se ha denominado "integración de pre-llegada o integración en el extranjero" se dirige a los potenciales inmigrantes que todavía están fuera del territorio nacional. Así una persona que desee inmigrar a Holanda, beneficiándose de la admisión o

79 Vid. GUIRAUDON, V., “ Contratos de integración para inmigrantes: tendencias comunes y diferencias en la experiencia europea”, Área: Demografía, Población y Migraciones Internacionales Real Instituto ElCano, ARI 43/ 2008. ILLAMOLA, M., "Los principios comunes como marco de la política de integración de inmigrantes de la Unión Europea y su incorporación a la política española de inmigración", en Revista de Derecho comunitario europeo, n. ${ }^{\circ}$ 38, 2008 pp. 155-182. KOOPMANS, R., "Trade-offs between equality and difference: Immigrant, integration, multiculturalism and the Welfare State in cross-national perspective", en Journal of Ethnic and Migration Studies, vol. 36, n. ${ }^{\circ}$ 1, 2010, pp. 1-26.

${ }^{80}$ Vid. las características del informe sobre el esfuerzo de integración y el llamado "accordo d'integrazione", en LA SPINA, E., op.cit., nota 67, esp. p. 476 y siguientes.

${ }^{81}$ MICHALOWSKI, I., "Modelos de acogida en Alemania, Francia y los Países Bajos: diseño y efectividad de los programas de acogida e integración”, en BILES, J., MICHALOWSKI, I. y WINNEMORE, L., Políticas y modelos de acogida. Una mirada transatlántica: Canadá, Alemania, Francia y los Países Bajos, Serie Migraciones, n. ${ }^{\circ}$ 12, Fundació CIDOB, Barcelona, 2007, pp. 67-92, en concreto p. 74. 
la reagrupación familiar, debe superar un examen, que se realizará en la embajada o consulado en el país de origen, para obtener un visado especial de entrada en el país (MVV) y, posteriormente, seguir un curso de instrucción cívica para renovar sus permisos ${ }^{82}$.

Por último, el contrato de integración francés se concreta en la obligación del inmigrante de respetar los valores franceses, al tiempo que el inmigrante se compromete a asistir a sesiones de formación sobre las instituciones francesas. Además, se exige un conocimiento adecuado de la lengua francesa, ofreciéndole cursos de idioma al final de los cuales deberá obtener el diploma inicial de lengua francesa (DILF). Estos cursos son en su primera convocatoria gratuitos, pero deberán ser costeados por el propio inmigrante en caso de que éste no los supere y deba examinarse de nuevo. La duración del contrato es inicialmente de un año, si bien puede prolongarse excepcionalmente por otro más, cuando así lo estime oportuno el prefecto, para completar la formación ${ }^{83}$.

Hasta ahora la única fiscalización de la decisión de denegar la reagrupación familiar bajo el criterio de la integración ha sido planteada por el juez holandés por medio de una cuestión prejudicial ante el TJUE sobre la compatibilidad del examen de integración cívica con la legislación comunitaria. El servicio jurídico de la Comisión emitió observaciones por escrito afirmando que la ley neerlandesa estaba violando el derecho a la reagrupación familiar. Sin embargo, el TJUE no se pronunció en el caso porque las autoridades neerlandesas habían concedido entretanto un permiso de residencia aunque la legislación neerlandesa se mantendría en los mismos extremos ${ }^{84}$.

En cualquier caso, la convergencia de tales "contratos", "acuerdos" y "cursos de integración" a nivel nacional advierte de la evolución de la integración como un proceso individual en el cual el nuevo inmigrante debe ser responsable de su éxito y tiene la obligación de integrarse. De este modo, la superación de tests o la inseguridad jurídica de la integración deviene una estrategia más de control ilimitado del Estado, incluso en aquellos casos que la admisión puede ser preceptiva habida cuenta del alcance del standard internacional de derechos humanos.

82 ENTZINGER, H., "Changing the rules while the game is on; from multicultualism to assimilation in the Netherlands", in BODEMANN, M AND YURDAKUL, G. (eds), Migration, Citizenship, Ethnos: Incorporation Regimes in Germany, Western Europe and North America, Palgrave MacMillan, New York, 2006, pp. 121-144.

${ }^{83}$ LOCHACK, D., "L’intégration comme injonction. Enjeux idéologiques et politiques liés à l'immigration", en Cultures et conflits, n. ${ }^{\circ}$ 64, 2006, pp. 131-147. CARRERA, S., op . cit., nota 70, p. 323 .

${ }^{84}$ Resolución del TJUE, 10 de junio de 2011, Bibi Mohammad Imran c. Minister van Buitenlandse Zaken, asunto C-155/11 PPU. 


\section{II.3. La admisibilidad de controles e inspecciones para perseguir el fraude legis}

Varios EEMM han introducido la posibilidad de realizar pruebas de ADN para demostrar los vínculos familiares, aunque la Directiva 2003/86/ CE admite un amplio margen de discrecionalidad para cada Estado a la hora de acreditar los integrantes de la familia objeto de la reagrupación familiar. El artículo 5.2, sólo determina que en casos de conveniencia para obtener la prueba de la existencia de vínculos familiares, los EEMM podrán realizar entrevistas con el reagrupante y los miembros de su familia o bien efectuar cualquier otra investigación que estimen necesaria. También la misma posibilidad se recoge en el artículo 16 apartado 4 sobre el matrimonio de conveniencia, por ser un caso concreto de fraude que los EEMM deben contrarrestar ${ }^{85}$. De ahí que además de sus normas generales de procedimiento, establece la posibilidad de llevar a cabo medidas de control e inspección si existen razones para sospechar sobre la existencia de un fraude o un matrimonio de conveniencia ${ }^{86}$, incluyendo uniones civiles y adopciones, sin hacer ninguna mención a la filiación biológica ${ }^{87}$.

La Comisión ha declarado que para ser admisibles en virtud de la legislación de la UE, esas entrevistas e investigaciones deben ser proporcionadas - es decir, no deben convertir en papel mojado el derecho a la reagrupación familiar - y respetar los derechos fundamentales, en particular, el derecho a la intimidad y el respeto a la vida familiar. Las diferencias o variantes existentes entre los EEMM que participan de la práctica de tales pruebas tiene un carácter excepcional que deviene operativo una vez "valorada" la ausencia de documentación fehaciente. De hecho, es común a todas ellas una amplia discrecionalidad normativa que se complementa con una aplicación selectiva de la prueba para ciertos individuos según el origen o procedencia. Los países del entorno europeo que han adoptado las pruebas genéticas para la comprobación del status de familiar en el procedimiento de reagrupación familiar son: Francia, Italia, España, Bélgica, Holanda, Reino Unido, Dina-

85 En 1997 se adoptó una Resolución sobre la lucha contra los matrimonios de conveniencia, adoptada por el Consejo de Justicia e Interior el 4 y 5 de diciembre de 1997. Resolución del Consejo 97/C382/01, de 4 de diciembre de 1997 (DOCE C n. ${ }^{\circ} 382$, de 16 de diciembre de 1997) y recientemente la contribución de Bélgica al respecto en el informe del European Migration Network: Misuse of the Right to Family Reunification: Marriages of convenience and false declarations of parenthood, European Commission, 2012, p. 1-25.

86 Por ejemplo, el Reino Unido reporta entre 5000 a 8000 casos de matrimonios forzados en 2009, frente a los ocho casos en Suecia durante el periodo septiembre 2010-2011.

87 Vid. artículo 5.2, 6.2 y 16.4 de la Directiva 2003/86/CE de 22 de septiembre de 2003. DOUE L 251/12 3.10.2003. 
marca, Alemania, Finlandia, Noruega, Suecia, Suiza, Austria, Estonia y Lituania ${ }^{88}$.

Máxime si es una práctica cuantitativamente generalizada, dado el número de países que si han recurrido a este método, sólo presentan un reconocimiento oficialmente excepcional que se somete con discrecionalidad o incluso arbitrariedad a sujetos en una situación familiar no suficientemente documentada. Por tanto, si existe consentimiento de "los interesados" no deja de ser una aquiesciencia forzada por imperativos de un mecanismo de entrada restrictivo o negador del derecho a la vida en familia. Unas exigencias que, dependiendo del país en cuestión, requieren al menos una inclusión normativa que pueda seguir unas coordenadas mínimas:

a) Debe existir una previsión en la ley y donde exista, es ineludible el cumplimiento de un requisito ulterior, que la ley sea inteligible. Esto implica adoptar disposiciones y fórmulas suficientemente precisas, que no puedan derivar para los sujetos de derecho en una interpretación contraria o arbitraria de la Constitución.

b) Debe adoptarse mediante resolución judicial especialmente motivada. En las investigaciones penales y de paternidad es conditio sine qua non para justificar la intervención y obtención de pruebas genéticas. No ocurre lo mismo en el procedimiento de reagrupación familiar que, salvo en el caso francés, es una praxis consular no sujeta al control de las autoridades judiciales que ni las ordenan ni autorizan, sino que se admiten en base a una amplia excepcionalidad ${ }^{89}$, persiguiendo una verdad biológica irrelevante para los "interesados".

c) Debe ser idónea, necesaria y proporcionada con un fin constitucionalmente legítimo. Esta medida concreta de practicar pruebas genéticas puede ser en, cierto modo, idónea y necesaria en aquellos casos en que los certificados emitidos por el país no son prueba fehaciente e indubitada de la relación de parentesco. Ahora bien, el sacrificio que impone valorando los derechos en juego sí resulta desmedido y desproporcionado en comparación con la gravedad de los hechos y de las sospechas existentes.

88 Vid. COM (2008) 610/3 Report from the Commission to the European Parliament on the Council on the application of Directive 2003/86/CE. European Migration Network: Adhoc Query on Conducting other investigation (Using DNA test) in family reunification cases, requested by HU EMN NCP, disponible en www.emnfi/.../HU_ad hoc_compilation_on_ Conducting_other_investigation_DNA-in_family_reunification_cases-wider_dissemination. pdf (última consulta 24/05/2015)

89 Vid. CABEZUDO BAJO, M.J., "La obtención transfronteriza de la prueba de ADN en la Unión Europea y su repercusión en España. El problema de las "búsquedas (del ADN) de familiares", en Revista de Derecho comunitario europeo, n. ${ }^{\circ}$ 40, 2012, pp. 737-765, p. 741. 
Por todo ello, si la regulación europea ha de cumplir dos requisitos básicos, como detalla Cabezudo en el denominado "uso forense de la tecnología del ADN": 1) la obtención de una prueba de ADN lo más fiable posible; 2) la obtención de una prueba de ADN lícita. Estos requisitos deberían ser recogidos como mínimos por la propia Directiva 2003/86/CE o al menos controlar a nivel nacional si son objeto de efectivo cumplimiento en sede administrativa en cada Estado miembro.

En primer lugar, sobre la fiabilidad, la obtención de la muestra, el análisis de su perfil en el laboratorio y el tratamiento del dato en la base de datos de ADN, habrá de ser realizado por personal cualificado. Si bien en la práxis de ciertos Estados son entes cualificados aquellos que analizan y obtienen la muestra ${ }^{90}$, no siempre es necesariamente así, y ambas cuestiones han de preverse legalmente.

En segundo lugar, si utilizando dichos métodos científico-tecnológicos adecuados se ha logrado una coincidencia, tras una búsqueda y comparación entre perfiles, es necesario formular dicho resultado en términos de probabilidad. El resultado del análisis del ADN no se formula ni interpreta en términos de probabilidad, sino de certeza absoluta, por lo que permite constatar por las autoridades diplomáticas el fraude le gis directamente para los nacionales de los terceros países estadísticamente sospechosos.

En tercer lugar y relacionado con las anteriores, la licitud de la prueba implica que ha sido obtenida con el máximo respeto a los derechos fundamentales afectados, según se proclaman en el CEDH (artículo 8), la CFDUE (artículos 7 y 8), y en las respectivas Constituciones nacionales. En definitiva, es necesario que sea recabada según las garantías previstas en normas de rango legal, en particular, como ocurre por ejemplo con las ya incluidas en normas procesales penales y civiles sobre la obtención y práctica de la prueba.

\section{Conclusiones}

El impacto de la Directiva sobre la armonización del ámbito de la reagrupación familiar a nivel europeo sigue teniendo un alcance más interesado que limitado. Desde el punto de vista de las buenas razones que militan en pro del abandono de una armonización de mínimos y que abogan en pro del acogimiento de un enfoque de armonización plena, los espacios de fragmentación jurídica siguen siendo considerables.

${ }^{90}$ LA SPINA, E., "DNA testing for Family Reunification in Europe. An exceptional Resource?", en Revista Migraciones internacionales, n. ${ }^{\circ} 22,6$, 3, 2012, pp. 39-74. 
Efectivamente, en pro de la armonización plena se ha alegado con frecuencia que la fragmentación jurídica perjudica a los EEMM, que no pueden estar seguros de que gozarán del margen de apreciación necesario para poner en marcha sus políticas migratorias. En cambio, uno de los efectos perversos del proceso de armonización de mínimos ha sido el carácter poco vinculante de la Directiva, llegando incluso a rebajar las disposiciones "opcionales" más favorables para el ejercicio del derecho por medio de fórmulas, quizás, excesivamente amplias ${ }^{91}$. Y precisamente en esta línea, ha tenido una incidencia directa el amplio margen de apreciación de los EEMM para articular a nivel interno aquellos aspectos de revisión normativa más deficitarios que cuentan, originariamente, con una articulación interesadamente más imprecisa. Algo en clara contradicción con el propósito enunciado por la Comisión en la Comunicación de 17 de junio de 2008, así como sucesivamente anunciado a nivel programático, que considera la reagrupación familiar como la clave para una inmigración exitosa, y un ámbito en el que la UE debe preferentemente desarrollar sus políticas. Este desiderátum ha sido compartido por la mayoría de los EEMM que se han mostrado de acuerdo con la posible revisión de la Directiva, a excepción de Holanda que se mantenía más partidaria de introducir meras clarificaciones conceptuales $^{92}$.

De igual modo, en sede jurisprudencial la voluntad de dar respuestas contenidas al margen de apreciación de los Estados ha marcado el primer examen de la Directiva 2003/86/CE, que ha advertido sobre el limitado alcance correctivo del Tribunal de Luxemburgo más allá de los criterios interpretativos del Tribunal de Estrasburgo. De un lado, sobre cómo se abordaría stricto sensu el derecho a la reagrupación, tal y como subyace en su normativa comunitaria, en puridad un carácter general y condicionado, mientras su negación se supedita a ciertas circunstancias excepcionales expresamente enunciadas y legitimadas ${ }^{93}$. O más bien, de otro lado, si continuaría

91 BULTERMAN, M., "Judgment of the Grand Chamber of 27 June 2006 [2006] ECR I-5769", en Common Market Law Review, n. . 45, 2008, pp. 245-259; BURGORGUE-LARSEN, L., "L'apparition de la Charte des droits fondamentaux de l'Union dans la jurisprudence de la CJCE ou les vertus du contrôle de légalité communautaire", en L'actualité juridique: droit administratif, n. ${ }^{\circ} 41,2006$, pp. 2286-2288; DRYWOOD, E., "Giving with one Hand, Taking with the Other: Fundamental Rights, Children and the Family Reunification Decision", en European Law Review, n. ${ }^{\circ}$ 32, 3, 2007, pp. 396-407.

${ }_{92}$ Las contribuciones recibidas al final del periodo de consultas fueron: 24 Estados miembros, 3 parlamentos nacionales, 21 organizaciones internacionales, 5 administraciones locales o regionales, 46 ONGs y 19 peticiones individuales. Summary of stakeholder responses to the green paper on the right to family reunification of third-country nationals, European Commision, Brussels, 1 June 2012, p. 1-26.

93 GROENENDIJK, K., Family Reunification as a Right under Community Law, op. cit. nota 55, esp. p. 219. 
reduciendo ratio personae la dimensión jurídica del derecho, obviando la debida conformidad de la normativa aplicable con el standard internacional de derechos humanos. En cualquier caso, tanto el reconocimiento excepcional como el ápice fiscalizador de la sentencia Chakroun limitando el alcance del derecho interno, muestran como se encuentra todavía demasiado alejado de una necesaria interpretación teleológica ${ }^{94}$.

En cualquier caso, la Directiva 2003/86, en su actual configuración y estado de aplicación, resulta poco adecuada para el logro del objetivo armonizador que proclama perseguir, dado que en línea de tendencia se ha movido más hacia la convergencia, limando por anuencia o aquiesciencia las diferencias más sustanciales que persisten entre las políticas internas, como paso previo a una futura armonización. Esta circunstancia tiene una lectura positiva: desde el punto de vista de su eficacia, dado que la homogeneidad habría obviado las diferencias reguladoras que preexistían entre los EEMM, insalvables en el proceso de negociación. Pero cabe otra lectura más negativa, esto es, desde el punto de vista de la transitoriedad y la seguridad jurídica.

Sin duda, tras doce años de la aprobación de la Directiva 2003/86/CE, la persistencia de ciertos problemas de aplicación práctica no resueltos son desafíos emergentes para un proyecto de armonización como tal. Básicamente, porque sobre la necesidad de hallar fórmulas de mayor firmeza y operatividad normativa, parece existir un debate polarizado o un punto de no retorno. De un lado, no se puede ocultar que el principio de armonización mínima tiene sus límites: una directiva solo puede tener eficacia armonizadora plena sobre aquello que regula. Si el legislador estatal es libre de regular como quiera lo que no entra dentro del ámbito de aplicación de la norma comunitaria, seguirán planteando especiales problemas los conceptos jurídicos indeterminados y las cláusulas generales. Y, de otro lado, la armonización plena también se ve limitada en la medida en que los EEMM que mantienen el status quo o que en lo sucesivo introduzcan medidas distintas a las previstas en la norma comunitaria, pueden plantear una reducción importante del nivel de protección que algunos EEMM ya les reconocen. La falta de sintonía entre el amplio margen de apreciación atribuido a los EEMM y la obstinación por la eficacia de las fórmulas de aproximación no logran superar in toto las, aún hoy, demasiadas resistencias "encubiertas" a la hora de configurar un ámbito de protección jurídica plena conforme a los estándares internacionales mínimos exigibles desde la propia UE.

94 Vid. ARRIAGA IRABURU, I., El derecho a la vida familiar de los extranjeros en la jurisprudencia de Estrasburgo, Eunsa, Navarra, 2004, p. 276, esto es, teniendo presente el objeto, en este caso la familia y el fin que se persigue, el desarrollo del ser humano dentro del espacio familiar, elemento natural y fundamental de la sociedad. 